\title{
Impact of Electric Power Pricing Reforms on the Japan's Industry and Household Sector
}

\section{Woojong Jung*}

Department of Socio-Environmental Studies, Faculty of Socio-Environmental Studies, Fukuoka Institute of Technology, Fukuoka, Japan. E-mail: jung@fit.ac.jp

\begin{abstract}
After the Fukushima nuclear power plant accident, Japan had an opportunity to advance its economic and energy policies to pursue stable energy supply, economic efficiency, environmental security, and safety. The accident not only raised concerns regarding the safety of nuclear power plants but also increased awareness regarding the effect of energy import growth on the economy and related issues such as the effect of imports on Japan's international competitiveness. This study simulates the impact on electricity prices using three potential scenarios for Japan. According to the results, the consumer price index (CPI) was larger than the corporate goods price index (CGPI) for Japan in all cases. In the simulation results, the CPI was observed to have an increased effect of $0.88 \%-3.59 \%$ against a $0.84 \%-3.41 \%$ increase in the CGPI. The surge in electricity prices significantly impacted the supply of electricity, gas, and heating and also the business services sector. The cost of policies that maintain safety, the increase in costs resulting from the overseas importation of fossil fuels, and the cost of promoting renewable energy in conjunction with the reutilization of nuclear power plants leading to higher electricity prices will also be considered in the future.
\end{abstract}

Keywords: Input-Output Analysis; Electric Power Price; Corporate Goods Price Index; Consumer Price Index

\section{Introduction}

Japan's basic energy policies have until recently been focused on Energy Security, Economic Efficiency, and the Environment (the so-called 3Es). However, following the Fukushima nuclear power plant accident, the element of safety has been added to this list. The Fukushima nuclear power plant accident was an opportunity to recognize anew the importance of safety, and even eight years after the accident occurred in March 2011, several challenges remain ${ }^{[1]}$.

The Ministry of Economy, Trade, and Industry has highlighted the following issues in the aftermath of the Fukushima nuclear plant accident ${ }^{[2]}$. First, there is concern about the safety of nuclear power plants. Since the Fukushima accident, all nuclear power generation in Japan has been suspended and safety inspections have been conducted. However, trust issues still exist among the Japanese people. Second, energy supply is erratic and greenhouse gas emissions are high. Since the accident, imports of petroleum and liquefied natural gas from the Middle East have grown as an alternative energy source to nuclear power, so the extent of dependency on the Middle East has increased, which has led to a greater risk of changes in foreign policy. Third, the rise in electricity costs has impacted the macroeconomics, affecting both industry and households. Six of the 10 power companies in Japan have already increased their regulated electricity charges, by $6.2-9.8 \%{ }^{[3]}$. Fourth, the gap in energy costs has broadened between international regions. Shell gas and petroleum from North America will have a significant impact on the composition of international energy supply

This is an open-access article distributed under the terms of the Creative Commons Attribution Non-Commercial License (http://creativecommons.org/licenses/by-nc/4.0/), which permits unrestricted non-commercial use, distribution, and reproduction in any medium, provided the original work is properly cited. 
moving forward, and this has already had a great impact in the drop in international competitiveness of energy-intensive industries in Japan, where the cost of importing energy is high.

Accordingly, this study assumes that there will be changes in electric power prices in conjunction with future changes in energy conditions both internationally and domestically, and thus analyzes the impact of power pricing reforms on the economy. In particular, the study adopts a 2011 version of a Japanese input-output table to quantitatively analyze the impact on CGPI and CPI at the time when the electric power prices for industry and households were reformed.

\section{Electric price trends and changes in the power market}

\subsection{International comparison of electric power price trends}

When trends in international prices over time are compared for household power, the relative increases in price seen in France and Japan are remarkable (Figure 1) ${ }^{[4]}$. At the same time, the rate of increase in Japan's industrial electric power prices is noteworthy, showing a roughly 37\% increase compared with the 2010 reference price (Figure 2) 25,6] $^{[5}$. In addition, when the trends in electric power prices for industry and households in Japan for the past several years are examined, although no significant changes can be seen before 2011, since the Great East Japan Earthquake in 2011 an increase in prices can be seen. When examining the change in prices from 2011 to 2015, prices for industry increased by about $14.6 \%$, while those for households increased by about $16.9 \%$, showing that the increase in household prices was greater than that for industry. The tax ratio has increased significantly since 2013, with the industry ratio accounting for nearly $8.5 \%$ and the household ratio nearly $8 \%$ as of 2015 . In other words, the major feature of power pricing in Japan in recent years seems to be increases in both base prices and the tax ratio.

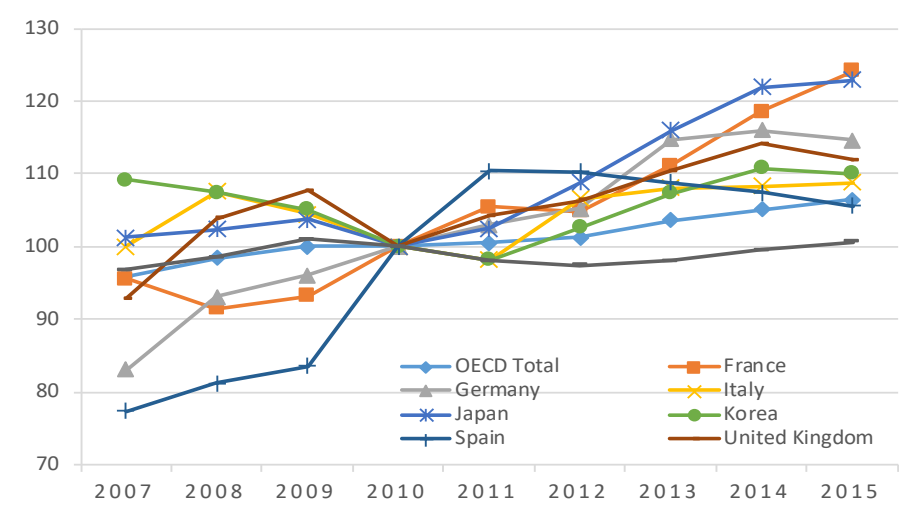

Figure 1. Household electric power price trends (100 for 2010). (Source: Figured by OECD/IEA [2017])

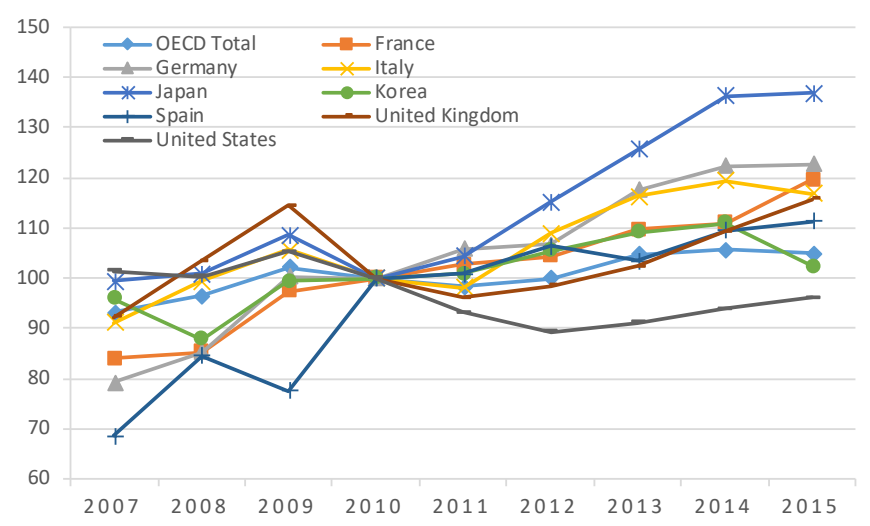

Figure 2. Industrial electric power prices trends (100 for 2010). (Source: Figured by OECD/IEA [2017])

2.2 Reutilization of nuclear power plants and the cost of dealing with the Fukushima nuclear 


\section{power plant accident}

Safety and the economy are primary concerns when examining the issues surrounding the reutilization of nuclear power plants, and since the Fukushima accident, safety has become the most important concern. The Nuclear Regulatory Commission is conducting a compliance review based on the new (amended in 2013) regulatory standards for commercial nuclear power reactors. These new regulatory standards for nuclear power reactors incorporate measures such as (1) the strengthening of response measures for major accidents; (2) adopting the latest technical know-how and introducing systems of mandatory conformance with the new standards, including the overall approval of nuclear power facilities; (3) introducing a system for approving extensions of operating periods; and (4) unifying the regulatory laws on nuclear reactors ${ }^{[7]}$. While maintaining safety is the highest priority challenge as per the new regulatory standards, the economy is also an essential consideration in the reutilization of nuclear power generation. The 2011 report presented to the Cost Evaluation Committee of the Energy and Environment Council states that the calculated cost of power generation, which had previously been 5.9 yen/kWh, has increased significantly to $8.9 \mathrm{yen} / \mathrm{kWh}^{[8]}$.

According to the Ministry of Economy, Trade and Industry, the TEPCO reform and 1F (Fukushima Daiichi Nuclear Power Plant) Problem Committee estimates that the current cost of nearly 11 trillion yen will increase to nearly 21.5 trillion yen in the future, which is approximately double the original amount. A breakdown of the new estimate indicates that decommissioning costs will be 8 trillion yen (originally 2 trillion yen), compensation will be 7.9 trillion yen (originally 5.4 trillion yen), decontamination will be 4 trillion yen (originally 2.5 trillion yen), and the costs of intermediate storage facilities will be 1.6 trillion yen (originally 1.1 trillion yen). The costs to be borne by TEPCO for coping with the accident are estimated to be 15.9 trillion yen (originally 7.2 trillion yen), and nearly 240 billion yen in additional costs are to be borne for new power introduced as a result of the retail deregulation that began in April 2016. Consequently, electricity expenses for power customers increased by about 18 yen per month for standard households. In addition, although the costs of decommissioning will be covered by the profits of TEPCO, the other costs will increase from the current 9 trillion yen to 13.5 trillion yen and will, therefore, need to be covered by a credit line based on government-issued securities. Even so, it is likely that the 22 trillion yen will increase further, depending on future conditions, so the focus will need to be on future developments. In addition to the issue of the cost of dealing with the accident, the efforts toward decommissioning the plant, which estimates claim will take nearly 40 years to complete, will require further analysis in terms of measures for dealing with contaminated water, securing a location for the disposal of radioactive waste, and safeguarding the health and safety of employees ${ }^{[9,10]}$. The cost increases for dealing with the accident arise, in addition to increases in operational costs, from the policy costs of the safety measures that are required for the reutilization of nuclear power and will lead to a reexamination of nuclear power's role as a main source of power generation in the future.

\section{Analysis methods and framework}

\subsection{Analysis methods}

This study adopts an input-output table for Japan (2011) as the main analysis method for measuring the ripple effect on electric power prices, using the equilibrium price mode ${ }^{[11]}$. Consequently, changes in producer prices were examined in other industries, and changes in corporate goods prices and consumer goods prices were measured as a result of the change in electric power prices. The analysis targeted 37 sectors of Japanese industrial classifications.

For this analysis, we employed an equilibrium price model to determine the impact on producer prices in other industries when the producer prices increase in a specific industry sector. A ripple analysis model for the effect of a price increase in a specific industry on producer prices in other industry sectors must treat the applicable industry (sector $k$ ) as an exogenous variable. The price balance equation of sector $\mathrm{j}$, with sector $k$ as an exogenous variable, can be written as follows.

$$
p_{1}=p_{1} a_{1 j}+p_{2} a_{2 j}+\cdots p_{k-1} a_{k-1 j}+p_{k+1} a_{k+1 j} \cdots p_{n} a_{n j}+\left(p_{k} a_{k+} v_{j}\right)
$$

Equation 1

Note that $\mathrm{j}=1,2, \cdots \mathrm{n}$ 
This equation can be expressed as follows using matrix symbols.

$$
\mathrm{P}^{*}=\mathrm{A}^{\prime *} \mathrm{P}^{*}+\left(\mathrm{P}_{\mathrm{k}} \mathrm{A}_{\mathrm{k}}^{\prime *}+\mathrm{V}^{*}\right)
$$

Equation 2

Note that $\mathrm{P}^{*}$ is a column vector that excludes Price $\mathrm{p}_{\mathrm{k}}$ of sector $k$ from the price column vector; $\mathrm{P}$. $\mathrm{A}^{*}$ is an input coefficient that excludes row $\mathrm{k}$ and column $\mathrm{k}$ from the original input coefficient matrix, A. In other words, $\mathrm{P}^{*}$ is the following input coefficient matrix, with sector $k$ as an exogenous variable.

$$
A^{*}=\left[\begin{array}{cccccc}
a_{11} & \cdots & a_{1 k-1} & a_{1 k+1} & \cdots & a_{1 n} \\
a_{21} & \cdots & a_{2 k-1} & a_{2 k+1} & \cdots & a_{2 n} \\
\vdots & \ddots & \vdots & \vdots & \ddots & \vdots \\
a_{k-11} & \cdots & a_{k-1 k-1} & a_{k-1 k+1} & \cdots & a_{k-1 n} \\
a_{k+11} & \cdots & a_{k+1 k-1} & a_{k+1 k+1} & \cdots & a_{k+1 n} \\
\vdots & \ddots & \vdots & \vdots & \ddots & \vdots \\
a_{n 1} & \cdots & a_{n k-1} & a_{n k+1} & \cdots & a_{n n}
\end{array}\right]
$$

Equation 3

$\mathrm{A}^{\mathrm{t} *}$ is a transposed matrix of $\mathrm{A}^{*} . \mathrm{A}_{\mathrm{k}}^{*}$ is a vector $\left[\mathrm{a}_{\mathrm{k} 1} \cdots \mathrm{a}_{\mathrm{kk}-1} \mathrm{a}_{\mathrm{kk}+1} \cdots \mathrm{a}_{\mathrm{kn}}\right]$ that excludes its own sector (sector $k$ ) from the row vector of sector $k$ of input coefficient matrix $A$ and is a distribution vector of sector $k$. $A_{k}^{t *}$ is a column vector with $A_{\mathrm{k}}^{*}$ transposed. $\mathrm{V}^{*}$ is a column vector that excludes sector $k$ from column vector $\mathrm{V}$ of the gross value-added ratio. Equation 4 is obtained by rearranging Equation 2 with $\mathrm{P}^{*}$.

$$
\mathrm{P}^{*}=\left[\mathrm{I}-\mathrm{A}^{\mathrm{t} *}\right]^{-1}\left(\mathrm{P}_{\mathrm{k}} \mathrm{A}_{\mathrm{k}}^{\mathrm{t}}+\mathrm{V}^{*}\right)
$$

Equation 4

If we assume that the rate of price increase by an industry sector when the price of sector $k$ increases by $\Delta \mathrm{P}_{\mathrm{k}}$ is $\Delta \mathrm{P}^{*}$, the following equation holds.

$$
\mathrm{P}^{*}+\Delta \mathrm{P}^{*}=\left[\mathrm{I}-\mathrm{A}^{\mathrm{t} *}\right]^{-1}\left[\left(\mathrm{P}_{\mathrm{k}}+\Delta \mathrm{P}_{\mathrm{k}}\right) \mathrm{A}_{\mathrm{k}}^{\mathrm{t} *}+\mathrm{V}^{*}\right]
$$

Equation 5

When producer prices of a specific industry sector increase, the ripple analysis model of producer prices in other industry sectors is obtained by subtracting Equation 4 from Equation 5.

$$
\Delta \mathrm{P}^{*}=\left[\mathrm{I}-\mathrm{A}^{\mathrm{t} *}\right]^{-1} \Delta \mathrm{P}_{\mathrm{k}} \mathrm{A}_{\mathrm{k}}^{\mathrm{t} *}
$$

Equation 6

Now, let us assume that producer prices in industry sector $k$ have increased by one unit $\left(\Delta \mathrm{P}_{\mathrm{k}}=1\right)$. In this case, the cost of each industry sector will rise by only $A_{k}^{t *}\left(=\left\{a_{k 1} \cdots a_{k k-1} a_{k k+1} \cdots a_{k n}\right\}\right)$, directly increasing the prices of other industry sectors by the same amount. That is, $A_{k}^{t *}$ is the direct price increase. $A_{k}^{t *}$ then has a ripple effect on each industry sector's input costs through $A^{t *}$. In other words, $A^{t *}$ causes $A_{k}^{t *}$ to increase in cost, pushing prices up. This increase in input costs results in a further increase in the cost of $\left(A^{t *}\right)^{2} A_{k}^{t *}$, once again pushing prices up. Price increases continue endlessly with this kind of iterative ripple process, triggering production price increases in industry sector $k$ and ultimately resulting in an extreme equilibrium price because of the ripple effect in each industry sector, from one production price to the next. The above ripple process can be expressed using the following equation, which is identical for the output model.

$$
\begin{aligned}
\Delta \mathrm{P}^{*} & =\mathrm{A}_{\mathrm{k}}^{\mathrm{t} *}+\mathrm{A}^{\mathrm{t} *} \mathrm{~A}_{\mathrm{k}}^{\mathrm{t} *}+\left(\mathrm{A}^{\mathrm{t} *}\right)^{2} \mathrm{~A}_{\mathrm{k}}^{\mathrm{t} *}+\cdots \\
& =\left[\mathrm{I}-\mathrm{A}^{\mathrm{t} *}\right]^{-1} \cdot \mathrm{A}_{\mathrm{k}}^{\mathrm{t} *}
\end{aligned}
$$

The price ripple expressed in Equation 6 not only affects domestic goods but also causes the prices of imported products to rise. Therefore, even in this model, Equation 8 is used with the self-sufficiency rate substituted to measure the price ripple effect only for domestic goods; imported goods are excluded from the model.

The ripple effect $\Delta \mathrm{P}^{*}$ (producer price change vector) on the producer prices (production costs) of each industry when the electric power price (sector $k$ ) changed by $\Delta \mathrm{P}_{\mathrm{k}}$ was calculated using the following Equation 8:

$$
\Delta \mathrm{P}^{*}=\left[\mathrm{I}-(\mathrm{I}-\widehat{\mathrm{M}}) \mathrm{A}^{t *}\right]^{-1} \Delta \mathrm{P}_{k}(\mathrm{I}-\widehat{\mathrm{M}}) \mathrm{A}_{k}^{t *}
$$

Equation 8

However, $\mathrm{P}^{*}$ is the column vector remaining after price $\mathrm{P}_{k}$ of the power industry (sector $k$ ) is subtracted from the producer price column vector $\mathrm{P}$ by sector. $\mathrm{A}^{*}$ and $\widehat{\mathrm{M}}$ are the input coefficient matrix and diagonal matrix, respectively, of import rates remaining after sector $k$ ( $k$ columns, $k$ rows) is subtracted from input coefficient matrix A and diagonal matrix of import rates $\widehat{M}$. Further, is the row vector remaining after the input coefficient of one's own sector ( $k$ columns, $k$ roles of sector $k$ ) is subtracted from the row $k$ vector of input coefficient matrix A. Furthermore, is a column vector with $A_{k}^{*}$ transposed. $\left[I-\left(I-\widehat{M}^{*}\right) A^{t *}\right]^{-1}$ is a transpose matrix of $\left[I-\left(I-\widehat{M}^{*}\right) A^{*}\right]^{-1}$.

Because changes in electric power price impact both CGPI and CPI, an analysis of corporate goods and consumer 
goods prices was also performed. $\Delta \mathrm{P}_{\mathrm{k}}$, which is exogenous to column vector $\Delta \mathrm{P}^{*}$ for the rate of increase in price by industry sector, is returned to sector $k$ and made into the original column vector $\Delta \mathrm{P}$. The weighted average can be calculated for $\Delta \mathrm{P}$, using equations 2 and 3 weighted by the total intermediate demand by industry sector $\left(\sum_{j=1}^{n} x_{i j}\right.$, $i=$ $1,2, \ldots n)$ and private consumption expenses by industry sector $\left(C p_{i}, i=1,2, \ldots n\right)$. Thus, the impact on the CGPI and CPI is calculated using the following Equations 9, 10:

$$
\begin{gathered}
\Delta C G P I=\sum_{i=1}^{n} \Delta p_{i}^{*} * \sum_{j=1}^{n} x_{i j} / \sum_{i}^{n} \sum_{j}^{n} x_{i j} \\
\Delta C P I=\sum_{i=1}^{n} \Delta p_{i}^{*} * C p_{i} / \sum_{i}^{n} C p_{i}
\end{gathered}
$$

The Leontief pricing model does not use demand- and supply-based market theory as its basis for determining price; instead, it provides an equilibrium price that reflects an extreme price ripple based on changes in production costs observed vertically in the input-output table. Therefore, this does not consider issues like ripple amplification caused by piggyback price increases, the interruption of ripples due to changes in public utility charges, or the substitution of raw materials. Cost increases due to changes in shipping expenses, power charges, crude oil prices, indirect taxes (i.e., consumption taxes, etc.), and other costs are theoretical values that ripple directly and indirectly when each industry sector passes on production prices on an as-is basis.

\subsection{Analysis outline}

The study simulated the impact on electric power prices using three scenarios in Japan. After the Great East Japan Earthquake, the price increase factor has been getting larger due to the cost effects of inspections on nuclear power plants and the rising price of imported natural gas from overseas. Accordingly, the following scenarios are set based on the varying rates of increase across power companies in Japan since 2011 ${ }^{[12-14]}$.

JS1 (High rate of increase (15.33\%) scenario): A simulation was run on the assumption that prices increased at the same rate as that of Hokkaido Electric Power Company, which has the highest price increase rate among power companies.

JS2 (Power company average (8.41\%) increase scenario): A simulation was run on the assumption that prices increased by $8.41 \%$, which is the average rate of price increase of the 10 main power companies.

JS3 (Low rate of increase (3.77\%) scenario): A simulation was run on the assumption that prices increased at the same rate as that of Chubu Electric Power Company, which has the lowest price increase rate among power companies, to simulate the ripple effects that the rises in electric power price in Japan have had on the economy and industry.

\subsection{Analysis conditions}

Note 1: The model reveals that the increase in costs caused by electric power price increases is passed on to production prices.

Note 2: The impact on corporate goods prices and consumer prices was analyzed as a ripple effect arising from changes in production prices.

Note 3: The price ripple effect is limited between industries; so the ripple and relationship with the household sector (e.g., an increase in goods prices becomes an increase in wages on the labor market, which leads to an increase in goods prices) was not taken into consideration.

Note 4: The substitution effect of demand caused by price increases was not considered.

Note 5: The technological level (input coefficient) was fixed at the 2005 level, so improvements in technology have not been taken into consideration.

Note 6: Owing to the nature of the analysis method, cost reductions resulting from a switch to imports or a shrinking of labor costs in response to an increase in raw material costs (including power) have not been modeled, so the cost increments have been added to the product price and sales volumes, therefore, remain unchanged.

\section{Impact of electric power pricing reforms on industry}




\subsection{Impact of high-rate price (15.33\%) increases (JS1)}

The ripple effect was simulated by assuming an increase in electric power prices throughout Japan at the rate of 15.33\% (April 2015), based on that of the Hokkaido Electric Power Company, which has the highest rate of price increase among major power companies in Japan. Table 1 shows that if the direct impact of production price change $\left(\Delta \mathrm{P}^{*}\right)$ on sector 22 is excluded, a production price rise effect is seen, with an increase of $4.71 \%$ in sector 24 , followed by $4.09 \%$ in sector 23 and $3.9 \%$ in sector 31 . The increases of $0.51 \%$ in sector $7,1.87 \%$ in sector 11 , and $2.43 \%$ in sector 4 show that the impact on the manufacturing sector is smaller than that for other industries, while the impact on the service industry tends to be large. This may be because the industrial structure of Japan is centered on the service industry. Further, looking at the change in CGPI, an increase of 3.41\% was seen across all industries. However, by sector, the largest increase was $0.49 \%$ for sector 22 , which was directly affected by the increases; followed by $0.41 \%$ for sector 34 and $0.29 \%$ for sector 25 . Furthermore, for the CPI, an increase of 3.58\% was seen for the industry as a whole, with the largest increase being $0.72 \%$ for sector 27 , followed by $0.58 \%$ for sector 25 and $0.54 \%$ for sector 35 . In this case, owing to the high rate of increase in electric power prices, the impact by sector is large, and there is a tendency for the impact on the service sector to be larger than that for the manufacturing sector.

\subsection{Impact of average-rate price (8.41\%) increases (JS2)}

Here, it is assumed that the rate of increase in electric power prices for the whole of Japan is based on the average rate of increase of the major power companies. First, for the change in production prices $\left(\Delta \mathrm{P}^{*}\right)$, if sector 22 , which was directly impacted, is excluded, the increase of $2.58 \%$ for sector 24 is the largest, followed by $2.24 \%$ for sector 23 and $2.14 \%$ for sector 31 . In the manufacturing industry, the increase of $1.93 \%$ for sector 9 was the largest; in addition, however, the nonmanufacturing sector dominates at the high end, so it can be said that the impact on the manufacturing industry is comparatively small. Further, observing the changes in CGPI, an increase of $1.87 \%$ can be seen across all industries, with an increase of $0.26 \%$ for the directly impacted sector 22 , followed by $0.22 \%$ for sector 34 and $0.15 \%$ for sector 25, thus demonstrating a large impact. In the manufacturing industry, the impact on sectors 10 and 6 was significant. In addition, for the CPI, an increase of $1.96 \%$ was seen across all industries and, by sector, the increase of $0.39 \%$ for sector 27 was the largest, followed by $0.32 \%$ for sector 25 and $0.30 \%$ for sector 35 , so it could be said that the impact was generally limited.

\subsection{Impact of low-rate price (3.77\%) increases (JS3)}

Here, a price increase was simulated on the assumption of a 3.77\% (May 2014) increase, based on the rate of increase for Chubu Electric Power Company, which was the lowest among the major power companies. First, for the change in production prices $\left(\Delta \mathrm{P}^{*}\right)$; if sector 22 , which was directly impacted, is excluded, the largest increase was $1.15 \%$ for sector 24 , followed by $1 \%$ for sector 23 and $0.96 \%$ for sector 31 . Further, looking at the changes in CGPI, an increase of $0.83 \%$ was seen across all industries, with the largest increase being $0.12 \%$ for sector 22 , followed by $0.1 \%$ for sector 34 and $0.07 \%$ for sector 25 . There were many service industry firms in the sectors that were minimally impacted, with an increase of $0.001 \%$ for sectors 18 and 33 and $0.002 \%$ for sector 30 . Therefore, both ends of the extent of impact were characterized by the predominance of the service industry. In addition, for CPI, there was an increase of $0.88 \%$ across all industries; by sector, the largest increase of $0.17 \%$ was for sector 27 , followed by $0.14 \%$ for sector 25 and $0.13 \%$ for sector 35 . 


\begin{tabular}{|c|c|c|c|c|c|c|c|c|c|c|}
\hline \multirow[b]{2}{*}{ No } & \multirow[b]{2}{*}{ Sector } & \multicolumn{3}{|c|}{ JS1 } & \multicolumn{3}{|c|}{ JS2 } & \multicolumn{3}{|c|}{ JS3 } \\
\hline & & $\Delta P^{*}$ & CGPI & $C P I$ & $\Delta P^{*}$ & CGPI & $C P I$ & $\Delta P^{*}$ & CGPI & CPI \\
\hline & Agriculture, forestry and fishery & 2.78946 & 0.06438 & 0.03343 & 1.53081 & 0.03533 & 0.01834 & 0.68599 & 0.01583 & 0.00822 \\
\hline 2 & Mining & 2.54273 & 0.13238 & -0.00005 & 1.39541 & 0.07265 & -0.00003 & 0.62532 & 0.03256 & -0.00001 \\
\hline 3 & Foods & 2.91885 & 0.09213 & 0.26659 & 1.60182 & 0.05056 & 0.14630 & 0.71781 & 0.02266 & 0.06556 \\
\hline 4 & Textile products & 2.43932 & 0.01512 & 0.03110 & 1.33866 & 0.00830 & 0.01707 & 0.59989 & 0.00372 & 0.00765 \\
\hline 5 & Pulp, paper and wooden products & 3.53570 & 0.09177 & 0.00428 & 1.94033 & 0.05036 & 0.00235 & 0.86951 & 0.02257 & 0.00105 \\
\hline 6 & Chemical products & 2.78903 & 0.15442 & 0.02503 & 1.53057 & 0.08474 & 0.01374 & 0.68589 & 0.03798 & 0.00616 \\
\hline 7 & Petroleum and coal products & 0.51704 & 0.01761 & 0.01134 & 0.28375 & 0.00966 & 0.00622 & 0.12715 & 0.00433 & 0.00279 \\
\hline 8 & Plastics \& Rubber & 3.11697 & 0.07618 & 0.00781 & 1.71055 & 0.04181 & 0.00429 & 0.76654 & 0.01873 & 0.00192 \\
\hline 9 & Ceramic, stone and clay products & 3.52833 & 0.04524 & 0.00186 & 1.93629 & 0.02483 & 0.00102 & 0.86770 & 0.01113 & 0.00046 \\
\hline 10 & Iron and steel & 3.00953 & 0.18421 & -0.00046 & 1.65158 & 0.10109 & -0.00025 & 0.74011 & 0.04530 & -0.00011 \\
\hline 11 & Non-ferrous metals & 1.87097 & 0.03990 & 0.00121 & 1.02676 & 0.02190 & 0.00066 & 0.46011 & 0.00981 & 0.00030 \\
\hline 12 & Metal products & 3.13621 & 0.06541 & 0.00320 & 1.72110 & 0.03589 & 0.00175 & 0.77127 & 0.01609 & 0.00079 \\
\hline 13 & Manufacture of general-purpose machinery & 3.00799 & 0.02308 & 0.00014 & 1.65074 & 0.01267 & 0.00008 & 0.73974 & 0.00568 & 0.00003 \\
\hline 14 & Manufacture of production machinery & 3.01388 & 0.01871 & 0.00010 & 1.65397 & 0.01027 & 0.00006 & 0.74118 & 0.00460 & 0.00002 \\
\hline 15 & Manufacture of business oriented machinery & 2.82252 & 0.01404 & 0.00202 & 1.54895 & 0.00770 & 0.00111 & 0.69412 & 0.00345 & 0.00050 \\
\hline 16 & Electronical device and parts & 2.97292 & 0.06669 & 0.00144 & 1.63149 & 0.03660 & 0.00079 & 0.73111 & 0.01640 & 0.00035 \\
\hline 17 & Electrical machinery & 2.75008 & 0.03133 & 0.02831 & 1.50920 & 0.01719 & 0.01553 & 0.67631 & 0.00770 & 0.00696 \\
\hline 18 & Information and communication machinery & 2.62498 & 0.00511 & 0.03881 & 1.44054 & 0.00281 & 0.02130 & 0.64554 & 0.00126 & 0.00954 \\
\hline 19 & Transportation equipment & 2.95723 & 0.14668 & 0.05545 & 1.62288 & 0.08049 & 0.03043 & 0.72725 & 0.03607 & 0.01364 \\
\hline 20 & Miscellaneous manufacturing products & 3.08768 & 0.05385 & 0.02854 & 1.69447 & 0.02955 & 0.01566 & 0.75933 & 0.01324 & 0.00702 \\
\hline 21 & Construction & 3.03114 & 0.06401 & 0.00000 & 1.66344 & 0.03513 & 0.00000 & 0.74543 & 0.01574 & 0.00000 \\
\hline 22 & Electricity, gas and heat supply & 15.33000 & 0.49157 & 0.34244 & 8.41286 & 0.26977 & 0.18793 & 3.77000 & 0.12089 & 0.08421 \\
\hline 23 & Water supply & 4.09849 & 0.02598 & 0.02730 & 2.24918 & 0.01426 & 0.01498 & 1.00791 & 0.00639 & 0.00671 \\
\hline 24 & waste management services & 4.71042 & 0.02825 & 0.00364 & 2.58500 & 0.01550 & 0.00200 & 1.15840 & 0.00695 & 0.00090 \\
\hline 25 & Commerce & 3.81213 & 0.29124 & 0.58764 & 2.09204 & 0.15983 & 0.32249 & 0.93749 & 0.07162 & 0.14452 \\
\hline 26 & Financial and insurance & 3.21615 & 0.11539 & 0.17692 & 1.76497 & 0.06333 & 0.09709 & 0.79092 & 0.02838 & 0.04351 \\
\hline 27 & Real estate & 3.47089 & 0.08926 & 0.72658 & 1.90477 & 0.04899 & 0.39874 & 0.85357 & 0.02195 & 0.17868 \\
\hline 28 & Transport and post & 2.61650 & 0.17588 & 0.12753 & 1.43590 & 0.09652 & 0.06999 & 0.64346 & 0.04325 & 0.03136 \\
\hline 29 & Communication and broadcasting & 3.34381 & 0.18396 & 0.15042 & 1.83503 & 0.10096 & 0.08255 & 0.82232 & 0.04524 & 0.03699 \\
\hline 30 & Public administration & 3.36986 & 0.00828 & 0.01329 & 1.84932 & 0.00454 & 0.00729 & 0.82873 & 0.00204 & 0.00327 \\
\hline 31 & Education and research & 3.90450 & 0.09456 & 0.10382 & 2.14272 & 0.05189 & 0.05697 & 0.96021 & 0.02325 & 0.02553 \\
\hline 32 & Medical service, health & 3.20711 & 0.01363 & 0.14852 & 1.76001 & 0.00748 & 0.08150 & 0.78870 & 0.00335 & 0.03652 \\
\hline 33 & Other public services & 3.06972 & 0.00781 & 0.04367 & 1.68461 & 0.00428 & 0.02396 & 0.75491 & 0.00192 & 0.01074 \\
\hline 34 & Business services & 3.18775 & 0.41439 & 0.04547 & 1.74938 & 0.22741 & 0.02495 & 0.78394 & 0.10191 & 0.01118 \\
\hline 35 & Personal services & 3.76482 & 0.02428 & 0.54796 & 2.06608 & 0.01333 & 0.30071 & 0.92586 & 0.00597 & 0.13476 \\
\hline 36 & Office supplies & 2.99875 & 0.00859 & 0.00000 & 1.64567 & 0.00471 & 0.00000 & 0.73746 & 0.00211 & 0.00000 \\
\hline 37 & Activities not elaewhere classified & 3.21731 & 0.03495 & 0.00021 & 1.76561 & 0.01918 & 0.00012 & 0.79121 & 0.00860 & 0.00005 \\
\hline & Total & & 3.41030 & 3.58555 & & 1.87152 & 1.96769 & & 0.83867 & 0.88177 \\
\hline
\end{tabular}

Table 1. Industrial impact of Japan’s electric power pricing reforms (Change rate; \%). (Source: Calculated by author)

\section{Results}

In this study, the economic ripple effect was examined in the event of price fluctuations in electric power, given the problems that Japan is experiencing in providing a stable energy supply and in the economy. The findings were as follows.

In the national study, in all cases, CPI was larger than the CGPI, and the impact of electric power price increases on consumers was significant (Figure 3). The CGPI is used to understand supply and demand trends for goods and as decision-making material regarding business trends and monetary policy by examining price fluctuations related to goods traded between companies. The CPI is used to observe price fluctuations, so it is an index that not only indicates the standard of living of a country's average citizen but is also extremely important in determining national economic policies. 


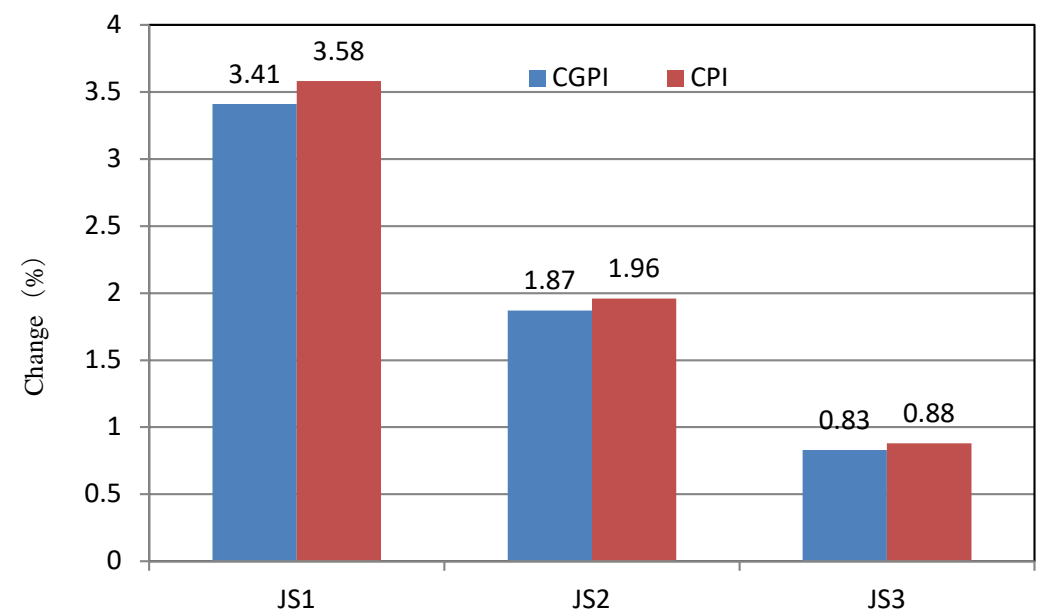

Figure 3. Economic effect of electric power pricing reforms. (Source: Figured by author)

The CGPI and CPI are important indices for understanding the state of an economy, but there is also a difference between them - the time difference of price fluctuations. In the case of the CGPI, when a price fluctuation arises, the changes are not immediately applied to consumer prices, so the increase factors are suppressed through cost reductions. However, there are limits to what companies can do, and before long, price increase factors spread to the CPI as well. In this analysis, for the JS1 case, the CPI increased by 3.59\% against a 3.41\% increase in the CGPI, while for the JS2 case, the CPI increased $1.97 \%$ against a $1.87 \%$ increase in the CGPI. For the JS3 case, the CPI is expected to increase $0.88 \%$ against a $0.84 \%$ increase in the CGPI.

For changes in production prices $\left(\Delta \mathrm{P}^{*}\right)$, the increases were high for sectors 24,23 , and 31 , while that for sectors 11 and 7 were low. With regard to the impact by sector, for CGPI, the increases were large for sectors 34,25 , and 10 , while for CPI, the increases were large for sectors 27,25 , and 35. In general, the impact on the service sector was high; in terms of the manufacturing industry, the impact was large for sectors 10, 6, and 5.

However, the industrial sector generally has a minimal impact on both the CGPI and CPI, so in this analysis, there was limited impact. Specifically, for the JS1 case, with the change in the CGPI, sector 18 increased by $0.005 \%$ and sector 33 increased by $0.007 \%$ with 27 out of all 37 industry sectors experiencing price increases below $0.1 \%$. Likewise, for the CPI, sector 10, sector 2, and sector 21 had an increase of $0 \%$ with 27 industry sectors having a price increase below $0.1 \%$. The JS2 case featured 32 industry sectors with a price increase below $0.1 \%$, while the JS3 case had 35 industry sectors, which indicates that the range of increases in the CGPI and CPI was small in many industry sectors. However, if the range of fluctuation in electric power prices increases in the future, this result will also change significantly. In other words, the cost of policies to maintain safety increases with the cost of imports of fossil fuels from overseas, and the cost of promoting renewable energy in conjunction with the reutilization of nuclear power plants might lead to electric power price increases in the future. In this national analysis, because a 2011 input-output model was used, even factors of social change such as the Great East Japan Earthquake are reflected in the results, while economic changes due to policy elements that followed such as "Abenomics" are not. A more realistic empirical analysis model must be constructed by reviewing the constraints of the equilibrium price model used in this study.

\section{References}

1. Agency for Natural Resource and Energy. White Paper 2016, Agency for Natural Resource and Energy [Internet]. Available from: https://www.enecho.meti.go.jp/about/whitepaper/2016pdf/.

2. The Ministry of Economy, Trade, and Industry. Strategic energy plan [Internet]. 2014. Available from: http://www.meti.go.jp/press/2014/04/2014041100/20140411001-1.pdf.

3. Hitoshi I. Electric power reforms 2020. Nikkan Kogyo Shimbun, Ltd; 2015.

4. Pollitt MG. Electricity liberalisation in the European Union: A progress report. 2011.

5. European Commission, Directorate-General for Energy. Quarterly report on European electricity markets [Internet]. 
2010; 3(4). Available from: https://ec.europa.eu/energy/en/data-analysis/market-analysis.

6. OECD/IEA. Energy prices and taxes statistics 2017. 2017.

7. Nuclear Regulation Authority. The New Regulatory Requirement for Nuclear Power Plants [Internet]. 2016. Available from: https://www.nsr.go.jp/data/000070101.pdf.

8. Energy·Environment Committee. Report on committee of cost verification, Energy·Environment Committee [Internet]. Ministry of the Environment; 2011.

Available from: https://www.env.go.jp/council/06earth/y060-100/mat02_3.pdf.

9. Nobuhiro H, Makoto T. A cash-out scheme for TEPCO's reparation for the Fukushima. Nuclear power station accident and its resulting unbundling [Internet]. National Graduate Institute for Policy Studies; 2011. Available from: http://www.grips.ac.jp/r-center/wp-content/uploads/11-02.pdf.

10. Park SJ. Estimate of economic consequences of a severe nuclear accident in Japan. Journal of Economics \& Business Administration 2005; 191(3): 1-15.

11. The Minister's Secretariat. Input-output table on 2011 [Internet]. 2011.

Available from: http://www.soumu.go.jp/toukei_toukatsu/data/io/ichiran.htm.

12. Kiyohide T. Development of customer segmentation mapping methodology of electric power companies using regional input-output analysis-Customer typification for development of price strategies-, Research report Y04003. Central Research Institute of Electric Power Industry (CRIEPI); 2005.

13. Takumi F. Analysis and countermeasures for the impact of rising electricity prices. Business \& Economic Review 2012; 31-52.

14. Yuta T, Hideyuki S, Kazuyuki A. Analysis of electricity market auction with renewable energy. Seisan Kenkyu 2014; 66(3): 309-313. 